\title{
Body of Knowledge: Ethical Responsibility in Engineering and Construction Education and National/Global Professional Bidding Practice
}

\author{
Enno "Ed" Koehn, Hani Tohme \\ Lamar University/City of Beaumont Water Utilities Division
}

\begin{abstract}
The efficient management of the cost and duration of a project involves the utilization of a productive labor force. This is true in both economically developed and developing countries. It is important, therefore, that ethically responsible decisions are required of project personnel. Some areas throughout the world, however, are experiencing a problem with ethics and corruption. Numerous firms, agencies, individuals, and educational institutions have also been involved with unethical activity. In order to fight the problem, a task force has been established by international engineering and construction firms. This paper reviews and investigates the level of corruption at the national/international level and presents a concept that may explain why it is happening. An approach is also presented, utilizing the application of a computer system, which may assist in eliminating or reducing the problem. Another solution to the corruption problem may be to develop an international code of ethics that could possibly sharply restrict those practices which U.S. engineers perceive as being unethical ${ }^{5}$. These concepts can be discussed at the university level in an educational seminar or course devoted to the study of professional and ethical responsibility in engineering.
\end{abstract}

Request for Proposal or Bid

The contracting system tends to be traditional throughout various regions of the globe $\mathrm{e}^{7,8}$. In this regard, there are different sources from which the invitation to bid or request for a proposal may originate. As an example, a contract may consist of a single package and, therefore, will be contracted either to a nominated supplier to the main contractor or to a direct supplier to the owner. In this case, the owner usually publishes the contract in the newspaper and invites companies to submit a proposal or bid on the project. The owner generally has a team of engineers and consultants who review the submittals to obtain the optimum price and recommend awarding the contract to a specific firm. In contrast, the owner may invite specific firms to bid or submit a proposal on the entire project, which may involve millions of dollars worth of work, and also effectively limit the number of potential submittals. Here, bribery and corruption could easily occur. The owner may also break the project into different sub-projects and invite companies to respond to various sections. This approach encourages small and medium companies to be involved with different sub-projects. Since many small, medium and large firms may compete with each other, the total price of the entire project may be reduced by

Proceedings of the 2005 American Society for Engineering Education Annual Conference \& Exposition Copyright (C) 2005, American Society for Engineering Education 
a substantial amount. However, the disadvantage of such an approach is that the owner must maintain control and supervise numerous sub-contractors.

\section{Constructor}

Once the contract is awarded to a particular firm, that company may invite numerous subcontractors to submit proposals or bids for the smaller sections of the project ${ }^{12}$. Under this method of invitation, the successful general contractor would have received quotations and may have negotiated prices in the earlier stage of the main contract. If exclusivity were agreed upon at that state, finalizing the supply contract becomes a matter of ironing out details and fine tuning the agreement.

However, if there was no exclusivity agreement, the successful general contractor may proceed in one of three scenarios ${ }^{9}$.

- Call for new bids or proposals with an open invitation especially to those organizations or firms who participated in the earlier phase of the main contract.

- Call for new bids with an open invitation to those organizations who participated and those who did not previously participate in the earlier phase of the main contract.

- Renegotiate prices with a short list of firms representing various organizations.

Again, bribery and corrupt practices may be introduced to the project at this time.

Negotiations

Negotiating may be the most difficult part of the whole process ${ }^{10}$. To be successful, it takes wit and extensive experience in and knowledge of the potential actions of the negotiator on the other side of the table. In many areas of the globe, professionals without negotiating capabilities will have difficulties securing contracts. Unfortunately, bribery can take place during the negotiation process.

Here, the track record of all the competitors in similar fields is important. Construction and consulting companies tend to specialize in certain fields in the industry. Investigating the history of the competitors throughout the years on similar projects can assist the firm with the information needed to be successful.

The record of the owner and/or the constructor vis-à-vis reputation, honesty, and satisfying business commitments must also be taken under consideration. Nevertheless, at times, bribes may be given to secure work.

\section{Awarding Contracts}

It is a common notion that the firm that submits the minimum bid or proposal is awarded the contract. However, it may also depend on the nature and complexity of the project. For example, a complex or large project may not be awarded to the firm offering the lowest price. In this

Proceedings of the 2005 American Society for Engineering Education Annual Conference \& Exposition Copyright $@$ 2005, American Society for Engineering Education 
regard, the history of the firm can play an important role in the decision-making process. Bribery and corruption may also influence the award of a contract.

Large contracts may need greater quality and specialized work by experienced people. In such cases, even a low bid or proposal placed by a relatively small and inexperienced firm may be rejected. The contract may be awarded to a company that has submitted a higher bid or proposal, but promises and has history of satisfactory performance. It has also been noticed that the reputation and previous experiences of the firm may also be a deciding factor. For example, a firm that has worked for a client in the past may be given preference in spite of a higher bid price $^{1}$.

\section{Ethical Behavior}

It has been reported that unethical behavior may be a commonplace occurrence in the U.S. construction industry ${ }^{19}$. A recent survey suggests that poor ethics may increase costs up to $5 \%$ in addition to giving the industry a poor image in the United States. In fact, a number of respondents indicated that, if needed, they would work with unethical firms.

Members of the Construction Management Association of America (CMA) were among the various respondents to the study. On a positive note, the executive director of the CMA mentioned that, as with safety, unethical actions can possibly be solved with the development, by engineers, of a sharp increased consciousness of ethical problems ${ }^{19}$.

\section{Unethical Behavior}

Unethical behavior commonly called cheating appears to be on the rise in university education. As an example, in a relatively recent study $82 \%$ of the engineering students have reported that they have cheated at least once ${ }^{16}$. In fact, students appear to be no longer embarrassed by it. At the national level, the largest numbers of academic misconduct cases are generally initiated in the college of engineering.

Engineering, especially civil engineering, involves the safety and welfare of the public.

Graduating students who have a false sense of their ability may reduce the level of safety for the general public. Another problem is that researchers have found that students who frequently cheated in high school also cheated in college ${ }^{16}$. Furthermore, they later disregarded polices at their place of employment falsifying records and quality control data. Therefore, it appears that cheating at the university and high school level must be reduced in order to maintain the concept of professionalism in engineering.

\section{Lesotho Infrastructure Project}

The Lesotho Highland water project has become a symbol of graft in international construction ${ }^{14}$. As an example, a government official is in prison due to his involvement in the corruption and a number of international firms have been accused of offering bribes to local intermediaries. These 
include Acres International Ltd., Oakville, Ontario; Lahmeyer International, GmbH, Bad Vilbel, Germany; and Sie Batignolles S.A., Paris, France.

However, a perception is developing that the increased publicity surrounding the Lesotho case may reduce the level of future corruption in construction. Furthermore, over 30 countries have recently outlawed corruption in foreign markets. Nevertheless, to some it is a surprise as to how prevalent corruption is and level at which it is accepted by professionals who consider themselves moral ${ }^{18}$. Therefore, it is recommended that world-wide credit agencies should begin investigating the corruption problem in construction.

\section{Bribery and Corruption}

Transparency International (TI), an independent organization based in Berlin, Germany, is involved with investigating corruption in business. It has collected data which indicate that officials in the construction industry are more likely to utilize bribery compared to those in other businesses ${ }^{17}$. In fact, TI has developed a ranking system for the level of corruption in the construction industry for various countries. The information is based upon the perception of roughly 800 individuals in 15 developing regions of the world ${ }^{6}$. As shown in Table 1 , Bangladesh appears to be the most corrupt nation in the world ${ }^{6}$. However, it is joined by numerous other nations which have emerging economies.

Companies from large nations such as China, India and Russia which are listed in Table 1 have also been found to bribe on an intolerable scale. Firms from the United States and those from Japan also have a tendency to bribe foreign officials. In contrast, companies from France, Germany and the U.K. were found to be less likely to bribe. In addition, organizations least likely to be involved with bribery include those from Sweden, Switzerland, Austria, and the Netherlands.

It is known that financing for a construction project requires lenders to secure a level of risk sharing among diverse participants with varying intentions. Profits may not be tied to the project's success and may be generated under a short time frame. In order to achieve results there may arise room in the short run for a special deal involving unlawful and corrupt actions ${ }^{13}$.

Who is guilty for this corruption? It is thought by some that it is due to the mismanagement of emerging economies primarily because of a shortage of professional human capital. Therefore, an education including a study of ethics and human resource development should be required of engineers throughout the world.

\section{Fighting Corruption}

In order to fight corruption, TI organized a meeting of large international construction organizations to study the problem. Furthermore, executives of major Engineering and Construction (E\&C) companies have established a multinational task force to develop anticorruption standards for world-wide E\&C procurement ${ }^{4}$. The group perceives that the concepts of transparency, accountability and responsibility are needed in the E\&C industry. 
Table 1 Corruption in Construction

\begin{tabular}{|clc|}
\hline $\begin{array}{c}\text { RANK } \\
\text { 1=Most Corrupt }\end{array}$ & $\begin{array}{l}\text { Representative } \\
\text { Countries }\end{array}$ & $\begin{array}{c}\text { Score } \\
\text { 0 Mostly Corrupt }\end{array}$ \\
1 & Bangladesh & 1.2 \\
2 & Nigeria & 1.6 \\
5 & Angola & 1.7 \\
6 & Kenya & 1.9 \\
7 & Indonesia & 1.9 \\
9 & Uganda & 2.1 \\
11 & Hati & 2.2 \\
13 & Cameroon & 2.2 \\
16 & Vietnam & 2.2 \\
17 & Ukraine & 2.4 \\
21 & Guatemala & 2.5 \\
22 & Albania & 2.5 \\
23 & Zambia & 2.6 \\
26 & Pakistan & 2.6 \\
29 & Russia & 2.7 \\
30 & India & 2.7 \\
33 & Argentina & 2.8 \\
36 & Panama & 3.0 \\
38 & Turkey & 3.2 \\
39 & Thailand & 3.2 \\
44 & China & 3.5 \\
45 & Mexico & 3.6 \\
50 & Latvia & 3.7 \\
\hline & & \\
\hline
\end{tabular}

Some large E\&C organizations have established guidelines which require their employees to consult company lawyers before developing a relationship with foreign officials. In addition, all payments must be accounted for. To assist smaller organizations to fight corruption, TI has also published a set of guidelines ${ }^{3}$.

The success of infrastructure projects is generally related to the management of risk in addition to the consideration of local political, social, cultural, and economic issues. This was mentioned at an infrastructure conference by firms established to assist organizations to assess the risk of working in international locations ${ }^{15}$. The foregoing efforts should make international E\&C more transparent and less susceptible to corruption.

In this regard, the Korean society of civil engineers believes that transparency is the key to optimum construction operations ${ }^{11}$. It is perceived that the characteristics of the Internet such as easy access and real time data can yield cost effective savings to providers and users.

Transparent procurement though the Internet can also be accomplished utilizing the following:

Proceedings of the 2005 American Society for Engineering Education Annual Conference \& Exposition

Copyright (C) 2005, American Society for Engineering Education 
- Electronic document systems

- Electronic bidding systems

- Electronic procurement systems

The foregoing may be considered to include the principal aspects of a modern consultant/contractor technical information system. Application of this transparent approach should reduce the level of corruption in construction.

Recently in Davos, Switzerland, 19 leading E \& C companies at a meeting of the World Economic Forum signed an agreement to reduce international corruption. Alan Boeckman, CEO of Fluor, commented that corruption has the effect of reducing the amount of capital available for global infrastructure projects. In addition, it is believed that some outstanding firms will not seek projects in parts of the globe where bribery is an accepted practice ${ }^{2}$.

The U.S. Department of Commerce estimates that contracts worth roughly $\$ 237$ billion were lost to U.S. firms between 1994-2002 due to suspected graft which is a violation of the U.S. Foreign Corrupt Practices Act ${ }^{2}$. This is a distinct problem in many countries where the officials who benefit from bribes and corruption are often the ones enforcing the anti-bribery laws. In order to reduce this approach to business practices, a study of ethics should be required of all engineering students.

Summary and Conclusions

Overall, the cost of various projects depends on numerous factors. These include, in part, the complexity of the project in question, quantity of material ordered, reputation and history of the user and contractor, specialized requirements, and the time allocated for fabrication and transportation. Bribery and corruption may also affect project costs. In addition, global competition plays an important role in determining worldwide prices. It is common knowledge that the law of "Supply and Demand" is always in effect. As an example, high demand in the international market causes prices to soar. On the other hand, a recession or slack period forces consultants, contractors and manufacturers to lower the prices in order to obtain work. Here, bribery may also be utilized to obtain contracts.

Unfortunately, of all major industries, it is perceived that international E\&C experiences a considerable amount of corruption ${ }^{6}$. For example, a study performed by TI indicates that, of all major industries, E\&C firms are most likely to bribe as well as utilizing the largest bribes ${ }^{17}$. In addition, numerous individual and firms have also been found guilty of various offenses. To assist in reducing corruption, it is strongly recommended that engineering and construction students, throughout the world, should include a study of ethics and human resource development in their program of study.

Recently, in order to reduce the level of corruption, numerous international E\&C firms have met to develop guidelines to eliminate, if possible, bribery on infrastructure projects. It is hoped that these guidelines and the publicity surrounding various court decisions will tend to reduce the Proceedings of the 2005 American Society for Engineering Education Annual Conference \& Exposition Copyright $($ 2005, American Society for Engineering Education 
level of global corruption. In addition, it is recommended that a transparent computer system be developed and utilized to electronically perform documentation, bidding and procurement services. This approach may strongly reduce the level of global corruption in E\&C projects.

\section{Acknowledgment}

The authors wish to recognize Ms. Linda Dousay for her assistance with the production activities involved with the preparation of this paper.

Bibliography

1. Ahuja, H.N. (1980). "Successful Construction Cost Control." John Wiley \& Sons, New York.

2. Binns, J. (2004). “Forms Sign Anticorruption Principles.” Civil Engineering, ASCE, 74(4), 20-21.

3. Business Principles for countering Bribery. (2003). Transparency International, Berlin, Germany.

4. "Fighting Corruption." ENR (Engineering News-Record), 251 (6), 11.

5. Humphrey, K. (2003). "The Ethics Corner.” Cost Engineering, AACE International, 45(12), 20.

6. How Countries Ranked in Corruption. (2003). Transparency International, Berlin Germany.

7. Koehn, E. \& Ahmed, M.U.(1999). "Production Rates for International Projects in Asia." Cost Engineering, 41 (8), 38-44.

8. Koehn, E., Ahmed, S.A. \& Jayanti, S. (2000). "Variation in Construction Productivity: Developing Countries." 2000 AACE International Transactions. Morgantown, WV.

9. Koehn, E. \& Ahmed, F. (2001.) "Production Rates for Urban/Rural Projects in Developing Areas." 2001 AACE International Transactions. Morgantown, WV.

10. Koehn, E., Tohme, H.J., and Shukla, A.P. (2003). "International Procurement of Constructional Materials for the Middle East." Proceedings, Second International Conference of Structural Engineering and Construction, Balkema Publishers, Elton PA.

11. Korean Society of Civil Engineers. (2002). "Transparency in Internet Environment.” International Roundtable at the ASCE National Conference, Washington, D.C.

12. Kumar, A. (2001). "Deliverable Based Service Contracts - A Challenge for Bidders." Cost Engineering 43 (5), 29-31.

13. Madono, Satow. (2002). "Games in Conflict of Interest." Presented at The ASCE National Meeting, Washington D.C.

14. Reina, Peter. (2003). "Bad to the Bone on Bribery." ENR (Engineering News-Record), 250 (25),41-44.

15. Rosenbaum, David B. (2000). "New Companies Help Firms Assess Risk if Working Abroad.” ENR (Engineering News-Record), 244 (24), 29.

16. Selingo, J. (2004). "The Cheating Culture." Prism, ASEE, 14(1), 24-30.

17. Sorting out the Sectors. (2003). Transparency International, Berlin, Germany.

18. Stansbury, Neil (2003). "Danger Signs of Corruption." To be published as a Transparency International Report, Berlin, Germany.

19. "Survey Points to Widespread Industry Lapses." (2004). ENR (engineering News-Record), 252(22), 13.

\section{ENNO "ED” KOEHN}

Enno "Ed" Koehn is Professor of Civil Engineering at Lamar University, Beaumont, TX. Professor Koehn has served as the principal investigator for several research and development projects dealing with various aspects of construction and has experience in the design, scheduling, and estimating of facilities. In addition, he has authored/co-authored over 200 papers in engineering education and the general areas of civil and construction 
engineering. Dr. Koehn is a member of ASEE, AACE International, ASCE, NSPE, Chi Epsilon, Tau Beta Pi, and Sigma $\mathrm{Xi}$ and is a registered Professional Engineer and Surveyor.

HANI J. TOHME

Hani J. Tohme is an Instructor of Civil Engineering at Lamar University, Beaumont, TX. Mr. Tohme has considerable consulting and construction experience in the Middle East and is a candidate for the Doctor of Engineering Degree at Lamar University. Currently, he is employed by the City of Beaumont Water Utilities Division. Mr. Tohme is a member of ASCE, and Chi Epsilon and is a registered Professional Engineer. 